\title{
Lack of association between cluster headache and PER3 clock gene polymorphism
}

\author{
Hilde K. Ofte ${ }^{1 *}$, Erling Tronvik ${ }^{2,3}$ and Karl B. Alstadhaug ${ }^{1,4}$
}

\begin{abstract}
Background: Cluster headache $(\mathrm{CH})$ is regarded as a chronobiological disorder. The hypothalamic biological clock may thus be involved in the pathophysiology, but few studies have actually investigated this in $\mathrm{CH}$ patients. A variable number tandem repeat (VNTR) polymorphism of the PER3 clock gene has been associated to preferred daily rhythm (chronotype) in several studies. We aimed to study the distribution of PER3 VNTR polymorphisms and chronotypes in a $\mathrm{CH}$ population.

Methods: We used blood samples from a biobank of $\mathrm{CH}$ patients for genetic tests, and invited all tested patients to complete the Horne-Ostberg Morningness-eveningness Questionnaire (MEQ), the Pittsburgh sleep quality Index (PSQI) and the Shift Work Index. Genotypes were compared to a previously tested population of 432 healthy students.

Results: One hundred forty nine patients were genotyped, and we found no difference in PER3 VNTR polymorphisms between patients and controls. Seventy-four patients completed the MEQ (54 men, 20 women, mean age 52.3 years \pm 13.4), and chronotypes were as follows: $12 \%$ morning-, $37 \%$ intermediate-, and $51 \%$ evening types. Compared with a previous Danish study of $\mathrm{CH}$ patients and controls, there were no difference in chronotype distribution. Sixty percent of patients were defined as bad sleepers (PSQI $>5$ ), and $51 \%$ of patients currently employed were shift workers.
\end{abstract}

Conclusions: No association between CH, PER3 VNTR polymorphism and chronotype was found in this study.

Keywords: Cluster headache, Chronotype, PERIOD3, Clock genes, Shift work, Horne-Ostberg Morningness eveningness questionnaire

\section{Background}

Cluster headache $(\mathrm{CH})$ is a periodic disorder, with a striking rhythmic occurrence of headache attacks and bouts. Up to $80 \%$ of patients report a predictable diurnal rhythmicity of attacks [1], and the attacks seem to occur most often at night between midnight and 04 a.m. [2], waking the patient from sleep. $\mathrm{CH}$ has been associated with shift work and chronic insomnia [2], and it has recently been demonstrated that $\mathrm{CH}$ patients in bouts have reduced REM sleep and fewer sleep arousals compared to controls [3]. The periodicity of attacks and apparent sleep disturbances imply that $\mathrm{CH}$ is a chronobiological disorder, and that the hypothalamic

\footnotetext{
* Correspondence: hkofte@gmail.com

'Department of Neurology, Nordland Hospital Trust, 8092 Bodø, Norway Full list of author information is available at the end of the article
}

biological clock (the suprachiasmatic nucleus, $\mathrm{SCN}$ ) may be involved in $\mathrm{CH}$ pathophysiology [4].

The SCN governs the biological rhythms of the body, oscillating in a strong 24-h cycle caused by transcription-translation loops of the so-called clock genes [5]. One of the key transcriptional loops running the clock is the CLOCK:BMAL1 cycle, where the $C L O C K$ and BMAL1 gene proteins join to form a complex that initiates transcription of the $P E R$ (PER1,2 and 3) and CRY (CRY1 and 2) gene families [6]. The protein products of these genes translocate to the nucleus and inhibit further transcription of the CLOCK:BMAL1 complex, thereby inhibiting their own transcription. $C K 1 \delta / \varepsilon$ gene coded kinases phosphorylate and degrade the PER/CRY proteins, allowing the cycle to start over again. The length of the

\section{Springer}


cycle varies between individuals and sets the period of the biological clock.

The internal clock cycle is reset every day by several external factors, of which light is the most important. Individual differences in the endogenous rhythms, in addition to sensitivity to light and sleep homeostasis, determine the biological basis to what we in daily life recognize as individual differences in diurnal preference (chronotype). Morning types (larks) seem to have shorter circadian cycles than evening types (night owls), and advanced sleep phase disorder (ASPD) and delayed sleep phase disorder (DSPD) are viewed as extremes in opposite ends of the continuum of diurnal preferences [7]. A variable number tandem repeat (VNTR, Table 1) of the DNA in the clock gene PERIOD3 (PER3, rs57875989) has been shown to correlate with diurnal preference in humans [8], and the short allele of the PER3 VNTR was associated to DSPD in two studies $[9,10]$.

A mismatch between the internal clock cycle and external time cues causes circadian misalignment, which over time may lead to various health problems [11]. Both chronotype and clock genotype contribute to how well individuals adapt to such misalignment $[12,13]$. If cluster headache is indeed a chronobiological disorder, an important question is whether the pathology resides in the biological clock itself, or in the adaptation between the clock and the environment. We aimed to study the PER3 VNTR distribution, chronotype and prevalence of sleep disturbances in a $\mathrm{CH}$ population, to evaluate if a specific genotype is associated with a higher risk of $\mathrm{CH}$.

\section{Methods}

\section{PER3 VNTR genotyping}

We used blood specimens obtained from a biobank located at St. Olavs Hospital in Trondheim. The biobank is founded by the Norwegian Advisory Unit on Headaches, and contains blood samples from headache patients living in the middle and northern part of Norway. All patients included in the biobank are consulted by a headache specialist, validating the headache diagnosis according to the International Classification of Headache Disorders (ICHD, version 2 and 3-beta) [14]. In addition, the patients must complete a form with questions regarding clinical characteristics, use of medication and work status. In spring 2014, all patients registered in the biobank with a diagnosis of $\mathrm{CH}$ were identified and

Table 1 Variable number tandem repeats

A variable number tandem repeat occurs in DNA when a pattern of one or more nucleotides is repeated, and the repetitions are directly adjacent to each other. In the human PER3 gene, the short allele contains four tandem 54-bp repeats, and the long allele has five such repeats. As each individual has two sets of alleles, this produces three possible genotypes: PER3 4/4, 4/5 and 5/5.
DNA extracted from the specimens. There was no kinship between the patients. DNA samples were purified, and polymerase chain reaction (PCR) amplification of the PER3 polymorphism performed according to previously validated methods $[9,15]$. We used forward primer 5'-CAAAATTTTATGACACTACCAGAATGGCTGAC-3' and reverse primer 5'-AACCTTGTACTTCCACATCAGTGCCTGG-3', as reported by Ebisawa et al. [9]. Gel electrophoresis was used to differentiate the PER3 genotypes. We used information on clincial characteristics from the biobank to compare the different genotypes.

The PER3 genotype distribution in the $\mathrm{CH}$ population was compared to that of a previously published population of 432 healthy Norwegian students (176 males and 256 females, mean age 22 years, $\mathrm{SD} \pm 2,6$ ) [15].

\section{Chronotyping and sleep assessment}

All the genotyped patients subsequently received an invitation by mail to participate in further studies, and were asked to complete and return the HorneOstberg Morningness-Eveningness Questionnaire (MEQ), Pittsburgh Sleep Quality Index (PSQI), and the Standard Shiftwork Index (SWI). All three questionnaires are validated in Norwegian translations.

\section{Horne-Ostberg morningness-eveningness questionnaire (MEQ)}

The MEQ is one of the most widely used and best validated tools for measuring diurnal preference [16]. It consists of 19 multiple-choice items, producing a score ranging from 16 to 86, with high scores indicating morning preference and low scores indicating evening preference. The initial chronotype cut-off points were validated for a population of young students, and as chronotype is strongly influenced by age and social factors, validated cut-off points for a middle-aged, non-shift working population have later been made [17]. We had no control group of our own for these data, but compared the results with a recent Danish study, chronotyping $275 \mathrm{CH}$ patients and 145 controls [1]. The authors kindly provided chronotype distribution in the Danish populations adjusted for age (private correspondence).

\section{Pittsburgh sleep quality index (PSQI)}

The PSQI is a validated, retrospective measure of subjective sleep quality and disturbances during the last month [18]. It consists of 19 items grouped into seven equally weighted component scores, with higher scores indicating poorer sleep quality. The maximum score is 21 , and a score above five indicates a poor sleeper. 


\section{Standard shiftwork index (SWI)}

The SWI is a standardized battery of questions developed to study the psychological and physiological impact of shift work [19]. We used it mainly to identify shift workers, as the small number of participants made detailed studies on adaptation to different shifts less reliable.

\section{Statistical methods, power calculation and ethics}

The null hypothesis was that there is no difference in PER3 polymorphism or chronotype distribution between $\mathrm{CH}$ patients and controls. We also hypothesized that in the subgroup analysis; there would be no correlation between PER3 genotype and MEQ-score, PER3 genotype and PSQI-score, and between the MEQ and PSQI. The frequencies of genotypes and chronotypes were compared with chi-square tests. Continuous variables were compared between genotypes with one-way ANOVA. The association between genotype and MEQ or PSQI scores was tested in a multiple, linear regression model, adjusted for age, gender and shift work. The level of significance was set at 0.05 for all statistical tests. No a priori power calculations were made.

The data were analyzed using the SPSS software package for Windows version 21 (SPSS Inc, Chicago, IL, USA). The Research Ethics Committee of Northern Norway reviewed the protocol and recommended the study. The Norwegian Data Protection Authority approved of data registration.

\section{Results}

\section{PER3 VNTR genotyping}

Genetic analysis of PER3 VNTR was performed in 149 $\mathrm{CH}$ patients (109 males and 40 females, mean age 54.1 years, $\mathrm{SD} \pm 14.0$ ). Table 2 shows the distribution of genotypes in 432 healthy controls, the total group of 149 $\mathrm{CH}$ patients, and in the subgroup of $74 \mathrm{CH}$ patients who were also chronotyped. When comparing the total $\mathrm{CH}$ population to healthy controls, there was no difference in PER3 VNTR polymorphism $\left(\chi^{2}(2)=0.016, p=0.992\right)$. The genotype distribution was in Hardy-Weinberg equilibrium, and the PER3 allele frequencies were the same for both populations ( 0.67 for the 4-allele and 0.33 for the 5 -allele). Table 3 shows clinical characteristics in the $\mathrm{CH}$ population, divided between the PER3 genotypes. There were no statistically significant differences between the three genotypes with regards to gender, age or clinical characteristics (calculations not shown). Unfortunately, there was no information available regarding episodic or chronic $\mathrm{CH}$.

\section{Subgroup analysis}

Eighty of the $149 \mathrm{CH}$ patients responded to our invitation and returned the questionnaires. Of these, 74 completed both the MEQ and PSQI forms and were included in subgroup analysis (54 men and 20 women, mean age 52.3 years \pm 13.4 ). The mean MEQ was $51.4 \pm$ 10.5 , and based on individual values we found the following chronotype distribution: 38 (51 \%) evening type, 27 (37\%) intermediate type, and nine (12\%) morning type. Table 4 shows chronotype distribution in the present $\mathrm{CH}$ patient subgroup, compared to the previously chronotyped $\mathrm{CH}$ population and healthy controls from Denmark [1]. There was no difference in chronotype distribution between the groups $(p=0.595)$.

The mean PSQI was $8.4 \pm 4.6$, and 44 of the responders $(60 \%)$ were defined as bad sleepers (PSQI $>5$ ). Table 2 shows mean MEQ and PSQI in each PER3 genotype. Seventy-six patients answered questions about shift work. Of the 49 patients currently employed, 25 (51\%) were shift workers and another nine $(18 \%)$ had previously worked shifts. Of the total group of 76 responders, 40 (52\%) were current or previous shift workers.

We found no association between PER3 VNTR polymorphism and chronotype $\left(\chi^{2}(4)=4.42, p=0.352\right)$. The multiple regression analysis adjusted for age, gender and shift work, showed no association between PER3 polymorphism and MEQ score. The PSQI scores seemed to decline from the PER3 4/4 to the PER3 5/5 genotype, but this was not statistically significant. Likewise, there was no association between MEQ and PSQI scores.

\section{Discussion}

We found no association between PER3 VNTR polymorphism and $\mathrm{CH}$ in his study. There seem to be a high proportion of evening types in this Norwegian $\mathrm{CH}$

Table 2 PER3 genotype distribution in 432 healthy controls and the total group of $149 \mathrm{CH}$ patients, and PER3 genotype distribution, MEQ and PSQI scores in the subgroup of 74 patients who completed both questionnaires

\begin{tabular}{|c|c|c|c|c|c|}
\hline \multirow[t]{2}{*}{ PER3 genotype } & \multirow[t]{2}{*}{ Controls } & \multirow[t]{2}{*}{$\mathrm{CH}$ patients } & $\mathrm{CH}$ patients & \multirow{2}{*}{$\begin{array}{l}\mathrm{MEQ}^{\mathrm{a}} \\
(\text { Mean } \pm \mathrm{SD})\end{array}$} & \multirow{2}{*}{$\begin{array}{l}\mathrm{PSQ}^{\mathrm{a}} \\
(\text { Mean } \pm \mathrm{SD})\end{array}$} \\
\hline & & & Subgroup $^{a}$ & & \\
\hline $4 / 4$ & $192(44.5 \%)$ & 67 (45.0 \%) & 32 (43.2 \%) & $52.5 \pm 9.8$ & $9.1 \pm 4.8$ \\
\hline $4 / 5$ & 191 (44.0 \%) & $65(43.5 \%)$ & 32 (43.2 \%) & $51.0 \pm 11.7$ & $8.1 \pm 4.6$ \\
\hline $5 / 5$ & 49 (11.5\%) & 17 (11.5\%) & $10(13.5 \%)$ & $49.5 \pm 8.9$ & $6.5 \pm 4.1$ \\
\hline Total/mean & 432 & 149 & 74 & $51.4 \pm 10.5$ & $8.4 \pm 4.6$ \\
\hline
\end{tabular}

Patients included in MEQ and PSQI analysis, $n=74$ 
Table 3 Clinical characteristics of 149 genotyped CH patients, divided between the three PER3 genotypes 4/4, 4/5 and 5/5

\begin{tabular}{|c|c|c|c|}
\hline PER3 genotype & $4 / 4$ & $4 / 5$ & $5 / 5$ \\
\hline Gender (M/F) & $50 / 17$ & $50 / 15$ & $9 / 8$ \\
\hline Age at inclusion (years) & $52.8, S D \pm 14.5$ & $55.6, \mathrm{SD} \pm 13.5$ & $53.9, \mathrm{SD} \pm 14.5$ \\
\hline Comorbid migraine without aura $(\mathrm{N})$ & $1(1.5 \%)$ & 0 & $3(17.6 \%)$ \\
\hline Comorbid migraine with aura $(\mathrm{N})$ & $5(7.5 \%)$ & $5(7.7 \%)$ & $1(5.9 \%)$ \\
\hline Comorbid tension type headache $(\mathrm{N})$ & $1(1.5 \%)$ & $1(1.5 \%)$ & 0 \\
\hline Age at onset (years) & $28.9, S D \pm 13.1$ & $31.0, S D \pm 14.5$ & $31.1, \mathrm{SD} \pm 13.9$ \\
\hline Headache intensity: strong (N) & $9(13.4 \%)$ & $4(6.2 \%)$ & $1(11.8 \%)$ \\
\hline Headache intensity: extra strong (N) & $37(55.2 \%)$ & $39(60 \%)$ & $10(58.8 \%)$ \\
\hline Attack duration (minutes) & $13.9, \mathrm{SD} \pm 8.5$ & $13.9, \mathrm{SD} \pm 9.1$ & $19.0, \mathrm{SD} \pm 11.0$ \\
\hline Number of attacks per month & $5.7, S D \pm 8.2$ & $4.0, S D \pm 7.6$ & $4.7, \mathrm{SD} \pm 11.2$ \\
\hline Number of attacks per day & $3.3, S D \pm 2.2$ & $3.6, \mathrm{SD} \pm 3.2$ & $3.0, S D \pm 2.1$ \\
\hline Total number of headache days in the last 3 months & $12.3, \mathrm{SD} \pm 12.1$ & $12.3, \mathrm{SD} \pm 11.0$ & 17.1, SD \pm 16.6 \\
\hline Total number of patients & $N=67$ & $N=65$ & $N=17$ \\
\hline
\end{tabular}

cohort, but we found no statistically significant difference in chronotype distribution when compared to a previously published Danish $\mathrm{CH}$ population and their healthy controls. The lack of association may be due to small sample size, or to the fact that MEQ is heavily influenced by age and social factors such as work schedules [20]. Thus, the activities of daily life may mask a true difference in clock period between individuals.

To the best of our knowledge, only one clock gene mutation has previously been investigated in a $\mathrm{CH}$ population. A single nucleotide polymorphism (SNP) in the downstream region of the Clock gene (T3111C) was studied in three separate Italian studies [21-23], all of which found no difference in genotype distribution between $\mathrm{CH}$ patients and healthy controls. The complexity of the biological clock was demonstrated in a genome-wide study from 2009, in which screening of small interfering RNAs showed that more than 200 genes were involved in clock functioning, regulating amplitude and period [24]. This illustrates that further research is needed to determine the role of clock involvement in $\mathrm{CH}$.

Sixty percent of the $\mathrm{CH}$ patients in our study were defined as bad sleepers, and sleep disturbances seem to be a consistent finding in studies of $\mathrm{CH}[1,2,4]$. A mean
PSQI of 8.4 is high even when compared to other headache populations. In a study from 2009, the authors found a mean PSQI of $5.9 \pm 3.0$ in migraine patients who suffered $\geq 8$ migraine days a month [25]. Sleep is one of the most important attack triggers in $\mathrm{CH}$ [2], but insomnia is not merely a result of nocturnal headache disrupting sleep, as sleep quality remains poorer compared to controls as long as one year after last headache attack [1]. Recent studies have shown that sleep homeostasis and the circadian oscillations of the SCN are more interconnected at the molecular level than previously thought [26], and the sleep disturbances in $\mathrm{CH}$ populations could therefore be a direct result of clock involvement in $\mathrm{CH}$ pathophysiology. The relationship between $\mathrm{CH}$ and sleep is further underlined by the association between $\mathrm{CH}$ and a missense SNP in the hypocretin receptor-2 gene (HRCTR2) reported in several studies, although a recent meta-analysis cast doubt on this finding [27].

Fifty-one percent of the patients in this cohort currently employed were shift workers. For comparison, about $33 \%$ of the general workforce in Norway work outside regular office hours (https://www.ssb.no/en/ arbeid-og-lonn/statistikker/yrkeaku/aar/2012-04-26\#content). Adaptation to shift work is influenced by both chronotype and clock genotype [12]. Night workers are

Table 4 Chronotype distribution in the present cohort of $74 \mathrm{CH}$ patients in percent, as well as chronotypes described in a Danish $\mathrm{CH}$ population and their healthy controls

\begin{tabular}{llll}
\hline & Norwegian CH patients (\%) & Danish CH patients (\%) & Danish controls (\%) \\
\hline Evening type (MEQ scores 16-52) & 51 & 45 & 43 \\
Neither type (MEQ scores 53-64) & 37 & 12 & 41 \\
Morning type (MEQ scores 65-86) & 12 & 275 \\
Total number (N) & 74 & 17 \\
\hline
\end{tabular}


more probable to be definite evening types compared to daytime workers [20], and it seems that morning types adapt better to daytime work than evening types. The $\mathrm{CH}$ patients in our study are mostly evening types, and we do not know if their evening preference is a result of the shift work or if they choose to work shifts because it suits them better. Theoretically, shift work may result in a circadian misalignment that could trigger $\mathrm{CH}$ in predisposed individuals. Further research is needed on the association between $\mathrm{CH}$ and shift work occupation.

\section{Strengths and limitations}

On the strong side, headache specialists had validated the $\mathrm{CH}$ diagnosis of all the participants prior to inclusion in the headache biobank. $\mathrm{CH}$ patients and controls were mainly ethnic Norwegians, thus suitable for genetic comparison. The controls were significantly younger than the $\mathrm{CH}$ patients, and there were more men in the patient group, but as genotype is a constant trait, and not associated with reduced lifetime expectancy or to a specific gender, this is irrelevant for our analysis. We used previously validated genetic tests and test tools, as well as validated Norwegian translations of the questionnaires.

The greatest limitation to our study concerns the issue of statistical power. Power calculations in genetic association studies rely heavily on the effect size that the candidate gene exerts on the disease or trait studied. This effect is unknown in our case, and could only be based on assumptions. It is generally accepted that common complex diseases are unlikely to be caused by a single locus of large effect, and that genotypic relative risks are likely to be in the range of $1-1.5$ [28]. $\mathrm{CH}$ is a rare disease, but it is most probably of a complex genetic origin. The limited access to patients makes large genetic studies on $\mathrm{CH}$ difficult to conduct, and our study is probably underpowered. This warrants caution in interpreting the results. However, genetic studies are important to develop a better understanding of the pathophysiology even in rare headache disorders. Despite its small sample size, we believe that this study adds to the knowledge of $\mathrm{CH}$ pathophysiology.

\section{Conclusion}

This study shows that $\mathrm{CH}$ patients have the same distribution of PER3 VNTR polymorphism and chronotype as healthy controls. There is a high frequency of sleep disturbances and shift work occupation in the $\mathrm{CH}$ population. Further research on the association between $\mathrm{CH}$, clock genes and their regulators are needed.

\section{Competing interests}

The authors declare that they have no competing interests.

\section{Authors' contributions}

HKO participated in design of the study and acquisition of the data, performed the statistical analysis, and drafted and revised the manuscript. ET participated in the acquisition of data and revising the manuscript. KBA conceived of the study and participated in its design and coordination, acquisition of data and revising the manuscript. All authors read and approved the final manuscript.

\section{Acknowledgements}

We would like to thank our colleagues in Denmark, Mads Barloese and co-workers, for providing age- adjusted chronotypes in the Danish $\mathrm{CH}$ population and their healthy controls. We are also indebted to Teresa Osland et al. for sharing with us PER3 data on the healthy controls. Thanks to Gøril Bruvik Gravdahl at the Norwegian Advisory Unit on Headaches for help with the acquisition of data.

\section{Author details}

${ }^{1}$ Department of Neurology, Nordland Hospital Trust, 8092 Bodø, Norway. ${ }^{2}$ Department of Neuroscience, Norwegian University of Science and Technology, Edvard Griegs gate 8, 7491 Trondheim, Norway. ${ }^{3}$ St.Olavs Hospital, Trondheim, Norway. ${ }^{4}$ The Arctic University of Norway, Troms $\varnothing$, Norway.

Received: 13 January 2016 Accepted: 24 February 2016

Published online: 29 February 2016

\section{References}

1. Barloese M, Lund N, Petersen A, Rasmussen M, Jennum P, Jensen R (2015) Sleep and chronobiology in cluster headache. Cephalalgia. doi:10.1177/ 0333102414564892

2. Ofte HK, Berg DH, Bekkelund SI, Alstadhaug KB (2013) Insomnia and periodicity of headache in an arctic cluster headache population. Headache 53(10):1602-12. doi:10.1111/head.12241

3. Barloese MC, Jennum PJ, Lund NT, Jensen RH (2015) Sleep in cluster headache - beyond a temporal rapid eye movement relationship? Eur J Neurol 22(4):656-e640. doi:10.1111/ene.12623

4. Weintraub JR (2003) Cluster headaches and sleep disorders. Curr Pain Headache Rep 7(2):150-6

5. Saper CB, Scammell TE, Lu J (2005) Hypothalamic regulation of sleep and circadian rhythms. Nature 437(7063):1257-63. doi:10.1038/nature04284

6. Zhang EE, Kay SA (2010) Clocks not winding down: unravelling circadian networks. Nat Rev Mol Cell Biol 11(11):764-76. doi:10.1038/nrm2995

7. Lamont EW, James FO, Boivin DB, Cermakian N (2007) From circadian clock gene expression to pathologies. Sleep Med 8(6):547-56. doi:10.1016/j.sleep. 2006.11.002

8. Dijk DJ, Archer SN (2010) PERIOD3, circadian phenotypes, and sleep homeostasis. Sleep Med Rev 14(3):151-60. doi:10.1016/j.smrv.2009.07.002

9. Ebisawa T, Uchiyama M, Kajimura N, Mishima K, Kamei Y, Katoh M, Watanabe T, Sekimoto M, Shibui K, Kim K, Kudo Y, Ozeki Y, Sugishita M, Toyoshima R, Inoue Y, Yamada N, Nagase T, Ozaki N, Ohara O, Ishida N, Okawa M, Takahashi K, Yamauchi T (2001) Association of structural polymorphisms in the human period3 gene with delayed sleep phase syndrome. EMBO Rep 2(4):342-6. doi:10.1093/embo-reports/kve070

10. Archer SN, Robilliard DL, Skene DJ, Smits M, Williams A, Arendt J, von Schantz M (2003) A length polymorphism in the circadian clock gene Per3 is linked to delayed sleep phase syndrome and extreme diurnal preference. Sleep 26(4):413-5

11. Scheer FA, Hilton MF, Mantzoros CS, Shea SA (2009) Adverse metabolic and cardiovascular consequences of circadian misalignment. Proc Natl Acad Sci U S A 106(11):4453-8. doi:10.1073/pnas.0808180106

12. Gamble KL, Motsinger-Reif AA, Hida A, Borsetti HM, Servick SV, Ciarleglio CM, Robbins S, Hicks J, Carver K, Hamilton N, Wells N, Summar ML, McMahon DG, Johnson CH (2011) Shift work in nurses: contribution of phenotypes and genotypes to adaptation. PLoS One 6(4), e18395. doi:10. 1371/journal.pone.0018395

13. Drake CL, Wright KP Jr (2011) Shift work, shift-work disorder, and jet lag. In: Kryger MH, Roth T, Dement WC (eds) Principles and practice of sleep medicine, vol 1, 5th edn. Elsevier Saunders, St. Louis, pp 784-98

14. Headache Classification Committee of the International Headache S (2013) The international classification of headache disorders, 3rd edition (beta version). Cephalalgia 33(9):629-808. doi:10.1177/0333102413485658 
15. Osland TM, Bjorvatn BR, Steen VM, Pallesen S (2011) Association study of a variable-number tandem repeat polymorphism in the clock gene PERIOD3 and chronotype in Norwegian university students. Chronobiol Int 28(9): 764-70. doi:10.3109/07420528.2011.607375

16. Horne JA, Ostberg O (1976) A self-assessment questionnaire to determine morningness-eveningness in human circadian rhythms. Int J Chronobiol 4(2):97-110

17. Taillard J, Philip P, Chastang JF, Bioulac B (2004) Validation of Horne and Ostberg morningness-eveningness questionnaire in a middle-aged population of French workers. J Biol Rhythm 19(1):76-86. doi:10.1177/ 0748730403259849

18. Carpenter JS, Andrykowski MA (1998) Psychometric evaluation of the Pittsburgh sleep quality index. J Psychosom Res 45(1):5-13

19. Smith C, Gibby R, Zickar M, Crossley C, Robie C, Folkard S, Tucker P, Barton J (2001) Measurement properties of the shiftwork survey and standard shiftwork index. J Hum Ergol 30(1-2):191-6

20. Paine SJ, Gander PH, Travier N (2006) The epidemiology of morningness/ eveningness: influence of age, gender, ethnicity, and socioeconomic factors in adults (30-49 years). J Biol Rhythm 21(1):68-76. doi:10.1177/ 0748730405283154

21. Rainero I, Rivoiro C, Gallone S, Valfre W, Ferrero M, Angilella G, Rubino E, De Martino P, Savi L, Lo Giudice R, Pinessi L (2005) Lack of association between the 3092T $\rightarrow$ C Clock gene polymorphism and cluster headache. Cephalalgia 25(11):1078-81. doi:10.1111/j.1468-2982.2005.00965.x

22. Cevoli S, Mochi M, Pierangeli G, Zanigni S, Grimaldi D, Bonavina G, Torelli P, Manzoni GC, Cortelli P, Montagna P (2008) Investigation of the T3111C CLOCK gene polymorphism in cluster headache. J Neurol 255(2):299-300. doi:10.1007/s00415-008-0719-8

23. Zarrilli F, Tomaiuolo R, Ceglia C, Lombardo B, Izzo B, Castaldo G, Pastore L, De Simone R (2015) Molecular analysis of cluster headache. Clin J Pain 31(1): 52-7. doi:10.1097/AJP.0000000000000075

24. Zhang EE, Liu AC, Hirota T, Miraglia LJ, Welch G, Pongsawakul PY, Liu X, Atwood A, Huss JW 3rd, Janes J, Su Al, Hogenesch JB, Kay SA (2009) A genome-wide RNAi screen for modifiers of the circadian clock in human cells. Cell 139(1):199-210. doi:10.1016/j.cell.2009.08.031

25. Seidel S, Hartl T, Weber M, Matterey S, Paul A, Riederer F, Gharabaghi M, Wober-Bingol C, Wober C, Group PS (2009) Quality of sleep, fatique and daytime sleepiness in migraine - a controlled study. Cephalalgia 29(6):662-9. doi:10.1111/j.1468-2982.2008.01784.x

26. Franken P, Dijk DJ (2009) Circadian clock genes and sleep homeostasis. Eur J Neurosci 29(9):1820-9. doi:10.1111/j.1460-9568.2009.06723.x

27. Weller CM, Wilbrink LA, Houwing-Duistermaat J, Koelewijn SC, Vijfhuizen LS, Haan J, Ferrari MD, Terwindt GM, van den Maagdenberg AM, de Vries B (2014) Cluster headache and the hypocretin receptor 2 reconsidered: A genetic association study and meta-analysis. Cephalalgia. doi:10.1177/ 0333102414557839

28. Evans DM, Purcell S (2012) Power calculations in genetic studies. Cold Spring Harb Protoc 2012(6):664-74. doi:10.1101/pdb.top069559

\section{Submit your manuscript to a SpringerOpen ${ }^{\circ}$ journal and benefit from:}

- Convenient online submission

- Rigorous peer review

- Immediate publication on acceptance

- Open access: articles freely available online

- High visibility within the field

- Retaining the copyright to your article

Submit your next manuscript at $\boldsymbol{s p r i n g e r o p e n . c o m ~}$ 